\title{
Bahoyak : Pengaruh Postmodern di dalam Pertunjukan Saluang Dendang di Minangkabau
}

\author{
Budi Alexander ${ }^{1)}$, Rafiloza $^{2)}$, Asril $^{3)}$ \\ ${ }^{12) 3)}$ Program Pascasarjana ISI Padangpanjang \\ Jl. Bahder Johan Guguk Malintang, Padang Panjang-Kota Padang Panjang, Sumatera Barat 27118 \\ Email: budialexander600@yahoo.com ${ }^{1)}$,rafiloza@yahoo.com ${ }^{2)}$, asril@yahoo.com ${ }^{3)}$
}

\begin{abstract}
This paper aims to discuss how the characteristics of the saluang show succeeded in being influenced by the postmodern that entered the lives of the people in Minangkabau. Bahoyak is a revealing medium used in the development of saluang jokes that have been somewhat influenced by postmodern culture. This is a new way of development in saluang kicking performances when society is easy to accept and there is no sense of burden when faced with postmodern culture. The people of Minangkabau especially fellow rang pagurau have the same hobby in enjoying the show saluang dendang, even though it is influenced by the development of the cultures that exist in Minangkabau society especially in the audience saluang dendang. The musical concept in saluang kicking on Bahoyak is prioritized with the sharpness of the kicker in making a sarcophagus and the development of the instrument in this show that makes the pagurau dragons dissolve in the show saluang dendang even though the show is already far away and experiencing a shift from the show tradisinya.
\end{abstract}

Keywords : Bahoyak, Minangkabau, postmodern, characteristic, saluang dendang

\begin{abstract}
Abstrak
Tulisan ini bertujuan untuk membahas tentang bagaimana ciri khas dalam pertunjukan saluang dipengaruhi oleh postmodern yang masuk dalam kehidupanmasyarakat di Minangkabau. Bahoyak merupakan sebuah media ungkap yang digunakan dalam pengembangan saluang dendang yang telah dipengaruhi oleh budaya postmodern. Hal ini merupakan sebuah cara pengembangan baru dalam pertunjukan saluang dendang ketika masyarakat dengan mudahnya menerima dan tidak ada rasa beban ketika dihadapkan dengan budaya postmodern. Masyarakat Minangkabau khususnya sesama rang pagurau mempunyai hobi yang sama dalam menikmati pertunjukan saluang dendang, sekalipun itu dipengaruhi oleh perkembangan budaya-budaya yang terdapat dalam lingkungan masyarakat Minangkabau. Konsep musikal dalam saluang dendang pada Bahoyak diutamakan pada kejelian pendendang dalam membuatkan sebuah pantun sindiran dan perkembangan instrument di dalam pertunjukan ini, sehingga membuat rang pagurau larut di dalam pertunjukan saluang dendang, meskipun pertunjukan tersebut sudah mengalami penggeseran dari pertunjukan tradisinya.
\end{abstract}

Kata kunci : Bahoyak, Minangkabau, postmodern, ciri khas, saluang dendang 


\section{Pendahuluan}

Jika dilihat perkembangan teknologi dan informasi, seni pertunjukan tradisi berusaha untuk memperjuangkan eksistensinya sebagai salah satu sarana hiburan bagi masyarakat pendukungnya. Jika dilihat pada dasarnya sebuah seni pertunjukan tidak hanya sebatas hiburan semata, melainkan memiliki fungsi sebagai, ritual,media pendidikan, dan dakwah. Salah satu kesenian tradisi yang masih eksis saat ini yang mengikuti zaman adalah pertunjukan bagurau saluang dendang.

Saluang dendang merupakan salah satu seni pertunjukan tradisi di Minangkabau.Tradisi ini telah tumbuh sejak lama, telah mengalami pertumbuhan dan perkembangan yang menarik.Perkembangan saluang tersebut di antaranya, saluang dangdut, bagurau oyak, dan saluang orgen. Pertunjukan saluang dendang yang lebih diutamakan dalam bentuk pertunjukannya, yaitu keakraban dan saling menyambung antara isi pantun si pendendang dengan penontonnya. Pertunjukan ini ditampilkan tidak hanya di pentas seni, tapi juga dilakukan di warung-warung kampung maupun di pasar. Hal ini ditandai dengan munculnya berbagai macam kelompok seni pertunjukan saluang dendang, seperti di pasar-pasar dan di berbagai kota di Sumatera Barat yang biasa disebut dengan bagurau lapiak ( Rina Oktavia $2017: 9$ ).

Banyak macam dendang yang dimainkan dalam pertunjukan bagurau, namun menurut pertunjukan tradisinya, bagurau selalu dimulai dengan tiga dendang wajib, yang pertama dendang pembuka Singgalang Alai, kedua dendang Situjuah, ketiga dendang Lintau Basiang dan nantinya di pengujung pertunjukan ditutup dengan dendang Jalu-Jalu.Jika dilihat dari perkembanganya Bagurau mengalami pergeseran baik dalam pendendangnya atau dendangnya maupun pada instrumen yang dipakai dalam pertunjukannya.

Salah satu perkembangan dalam pertunjukan Bagurau yaitu dengan menambahkan orgen tunggal sebagai pengiringnya.Semenjak dihadirkannya orgen tunggal sebagai pengiring dalam pertunjukan ini, bagurau semakin mengalami pergeseran besar dan menimbulkan fenomena baru. Hasil wawancara dengan Erista (tukang dendang) mengatakan pendendangpendendang yang menyanyikan dendang di pagurauan bukan lagi pandendang yang mempunyai skill atau keahlian dendang pada umumnya, namun kebanyakan pendendang muda yang berlatar belakang penyanyi orgen (Erista, Wawancara 3 Januari 2018 di Batu Sangkar).

Perkembangan ini juga mengacu pada penampilan dan gaya yang dipakai dalam bernyanyi orgen tunggal, seperti warna rambut yang gonta-ganti, handphone, tas, dan lain sebagainya yang mereka gunakan sebagai penunjang penampilan.Pengaruh dari perkembangan pemikiran masyarakat tidaklah mengubah pandangan mereka dalam menyaksikan pertunjukan saluang dendang. Mereka tetap tidak ada kerisihan bahkan hal tersebut menjadi suatu kesenangan baru yang mereka rasakan dalam pertunjukan. Di lain sisi, hal tersebut menjadi kegelisahan bagi pengkarya dan menimbulkan pertanyaan-pertanyaan ketika jati diri sebuah tradisi sudah mulai berubah.

\section{Pembahasan}

Salah satu perubahan yang terjadi disebabkan dengan pengaruh posmodern yang masuk dengan cara mudahnya mempengaruhi pemahaman pemikiran masyarakat yang berlatar belakang konsep rhizoma(ubi jala) (Akhyar Yusuf Lubis 2014 : 184) . Posmodern yang dimaksud adalah perubahan paradigma dari era sebelumnya, sedangkan rhizoma adalah sebuah gaya baru yang masuk ke dalam pertunjukan saluang dendang, sehingga ciri khas dalam pertunjukan saluang dendang yang biasa disebut dengan saluang klasik sudah mulai tak terlihatketika diintervensi oleh lagu-lagu pop, lagu dangdut, lagu qasidah, bahkan sampai lagu India. Akhirnya jati diri dalam pertunjukan saluang dendang klasik yang sesungguhnya sudah mulai tidak terlihat. Selain itu ditambah dengan rasa kesenangan dan kenikmatan oleh sebagianrang pagurau(penonton)dan pelaku gurau (tukang saluang dan pendendang)dalam menikmati pertunjukan tersebut, dan sikap yang ditampilkan oleh pendendang dengan begitu santainya bercanda gurau sesama mereka dan melakukan aktivitas seperti berfoto-foto dan lain sebagainya selama pertunjukan gurau berlangsung. Hal ini memperlihatkansebagian dari mereka sama sekali tidak merasakan kerisihan ketika dihadapkan dengan musik yang diluar konteks tradisi dalam pertunjukan saluang dendang.

Fenomena bagurau ini mendorong pengkarya untuk mengangkat kedalam sebuah komposisi musik yang mengambil pendekatan posmodern,dengan menggarap karya berlandaskan konsep estetika dari postsmodern yaitukitsh dan pastiche. Pastich yang dimaksud adalah ketika idiom dari objek seni musik tradisi itu sendiri yang dikomunikasikan dengan semangat baru, sedangkan kitsh sendiri adalah estetika simulasi yang mereproduksi objek-objek dengan skala yang lebih besar atau kecil yang mengimitasi material dan mengkomunikasikannya secara sumbang (Yasraf Amir Piliang, 2003:218).

Bedasarkan pemaparan tersebut, pengkarya menafsirkannya melalui penggarapan idiom tradisi yang terdapat pada kesenian bagurau ke dalam sebuah pertunjukan gurau dengan pengembangan yang dipengaruhi oleh postmodern dengan idiom beberapa dendang di dalam pertunjukan saluang dendang, seperti dendang Singgalang, dendang Jalu-Jalu, Manjalang Subuah, dan dendang-dendang lainya. Pengkarya menggarap perkembangan bagurau ini terhadap penggalan-penggalan dendang yang dilahirkan dengan kreativitas baru, sehingga menjadi sebuah pertunjukan gurau versi baru yang diberi nama dengan "'Bahoyak ". Bahoyak diartikan sebagai semangat atau spirit yang masuk dan menjiwai ke dalam diri seorang penikmat saluang dendang dengan pandangan yang bisa diterima dalam lingkungan bersama. 


\section{A. Rancangan Konsep Garapan.}

Seperti yang telah dijelaskan sebelumnya, bahwa karya "'Bahoyak" berangkat dari sebuah fenomena pertunjukan saluang dendang yang mengambil pendekatan posmodern dengan didasari konsep rhizoma dalam pertunjukan saluang dendang. Perubahan yang terjadi dalam struktur pertunjukan saluang dendang tidak menjadi pengaruh besar bagi sebahagian rang pagurau.Perencanaan yang akan dibangun berdasarkan pemaparan ide pengkarya di atas, karya ini akan diwujudkan ke dalam karya komposisi musik nusantara dengan menafsirkannya melalui penggarapan idiomidiom tradisi yang terdapat pada kesenian bagurau.Idiom yang pengkarya pakai adalah dendang Jalu-Jalu,dan tidak tertutup kemungkinan memakai idiom dendangdendang lainnya.

Pada karya ini pengkarya membagi karya kedalam dua bagian, bagian pertama dendang Jalu-Jalu digarap dengan tidak seutuhnya hanya mengambil bagian awal dendang.

Dengan notasi :

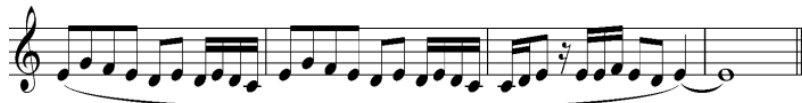

Pada bagian kedua pengkarya mengembangkan dendang Jalu-Jalu pada penggalan dendang yang kedua.

Dengan notasi :

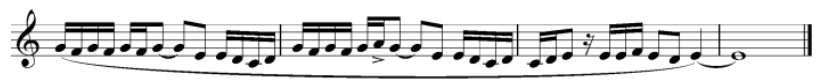

Mengenai bentuk dan struktur konsep pertunjukan, Suka Hardjana (Coret-coret Musik Kontemporer Dulu Dan Kini, 2003: 73) mengatakan bahwa dalam bentuk dan struktur material (bunyi, suara, nada, ritme, harmoni dan seterusnya) dan non material (dinamik, sifat, watak, rasa dan sebagainya) di akomodasikan. Pendapat Suka Hardjana ini lebih bersifat umum sehingga dalam pelahiran karya komposisi musik nusantara ini akan dilakukan penggarapan yang sesuai dengan ketentuan musik konvensional baik terhadap aspek material (bunyi, suara, nada, ritme, harmoni dan seterusnya). Pengkarya melakukan penyusunan material musikal dengan mempertimbangkan material yang bersifat seperti, dinamik, watak, rasa, dan sebagainya. Selain itu, durasi dan materi garapan juga dipertimbangkan agar pertunjukan tidak terkesan monoton, "durasi sajian yang panjang dengan banyak pengulangan-pengulangan, akan membosankan bagi yang kurang akrab dengan kesenian itu’' (Rahayu Supanggah, 2005 : 285 ).

\section{Ciek Raso}

Perencanaan pada penggrapan karya "Bahoyak" bagian pertama karya ini diberi judul "Ciek Raso". Dalam karya "Ciek Raso". Pada bagian ini suasana yang dihadirkan adalah heboh atau ribut. Bagian ini disampaikan dengan sorak-soray player yang membagi tempat dalam tiga bagian, dan masing-masing pemain tersebut muncul satu persatu dengan sorak sorai versi mereka masing-masing. Alasan pengkarya menghadirkan suasana tersebut, pengkarya menggambarkan rang pagurau yang hadir didalampertunjukan saluang dendang.

Pada karya "Ciek Raso", lebih terfokus kepada permainan santai dan rasa enjoy namun tidak terikat dalam satu idiom. Sesuai dengan konsep kitch dalam penggarapan ini, pengkarya memberikan kebebasan pada player dalam mengeksplorasi bunyi dan materi yang diberikan namun tetap terikat dalam satu rasa (ciek raso).Dalam perwujudannyadihadirkan dengan Instrumen yang akan digunakan adalah instrumeninstrumen lokal seperti plastik rokok, pupuik lambok, dan lebih banyak menggunakan vokal. Alasan pengkarya memakai instrumen tersebut karena pengkarya membutuhkan keluasan dalam mengeksplorasi garapan sesuai dengan capaian dalam mewujudkan "Ciek Raso'.Karya ini diawali dengan teriakan seorang pemain kemudian disambung dengan sahutan vocal wanitakemudian langsung disambut dengan plastik rokok yang dimainkan di mulut, lansung direspon oleh vokal cowok, kemudian disahut kembali oleh vokal wanita, kemudian di sahut lagi oleh vokal cowok kelompok dua, kemudian lansung disambut dengan permainan plastik rokok dengan dua frase kemudian disambung dengan melodi pupuik lambok, kemudian diiringi oleh vokal bersama.

\section{Byobana}

Bagian kedua karya ini diberi judul "Bayobana", penggarapan karya ini difokuskan pada penggarapan idiom tradisi yang dikembangkan dengan pola ketukan instrument perkusi, pukulan gendang sarunaidan darbuka,diberi background nada-nada yang harmonis dengan menggunakan media ungkap instrumen melodi seperti saluang, seruling, kecapi sunda, mandolin, talempong dan vokal.Capaian pada bagian kedua ini yang ingin pengkarya sampaikan, adalah semangat baru yang lahir didalam diri pengkarya melalui media ungkap idiom tradisi dengan gaya garap menggunakan konsep pastiche.

Tabel 1. Penjelasan alur, suasana, bentuk musik, teknik garap serta penggunaan instrumen

\begin{tabular}{|c|c|c|c|}
\hline $\begin{array}{l}\text { Bagian } \\
\text { (Sub } \\
\text { Judul) }\end{array}$ & $\begin{array}{c}\text { Penjelasan } \\
\text { Alur, Suasana, } \\
\text { Bentuk Musik }\end{array}$ & $\begin{array}{c}\text { Penggunaan } \\
\text { Instrumen }\end{array}$ & $\begin{array}{c}\text { Teknik } \\
\text { Garapan }\end{array}$ \\
\hline $\begin{array}{l}\text { Bagian } 1 \\
\text { Ciek raso }\end{array}$ & $\begin{array}{l}\text { Konsep alur: } \\
\text { Akan } \\
\text { menggambarka } \\
\text { n suasana awal } \\
\text { dalam } \\
\text { pertunjukan } \\
\text { saluang } \\
\text { dendang dengan } \\
\text { konsep kitsh } \\
\text { Konsep } \\
\text { suasana: } \\
\text { suasana, heboh, } \\
\text { enjoy, senang, } \\
\text { santai. }\end{array}$ & $\begin{array}{l}\text { Intruments, plastik } \\
\text { rokok,pupuik } \\
\text { lambok, saluang, } \\
\text { lebih banyak } \\
\text { vokal pada bagian } \\
\text { satu ini, alasan } \\
\text { dalam } \\
\text { penggunaan } \\
\text { instruments untuk } \\
\text { menghadirkan } \\
\text { suasana yang } \\
\text { heboh, santai, } \\
\text { senang. }\end{array}$ & $\begin{array}{l}\text { Teknik } \\
\text { garapan } \\
\text { yang } \\
\text { digunaka } \\
\mathrm{n}, \\
\text { unisono, } \\
\text { teknik } \\
\text { tanya } \\
\text { jawab, } \\
\text { dinamika }\end{array}$ \\
\hline
\end{tabular}




\begin{tabular}{|l|l|l|l|}
\hline Bagian II & Konsep alur: & Talempong, & Teknik \\
Bayobana & $\begin{array}{l}\text { Suasana baru } \\
\text { seruling, gendang } \\
\text { yang }\end{array}$ & $\begin{array}{l}\text { Garanai, mandolin, } \\
\text { saran }\end{array}$ \\
& dipengaruhi & vocal, gitar bass, & Memakai \\
& oleh pemikiran & darbuka lekdaw, & unisono \\
& postmodren & kecapi sunda, & interlocki \\
& dengan konsep & saluang & ng, \\
& pastiche. & & dengan \\
& Konsep & & sistem \\
& suasana: & & harmoni, \\
& Manis,ringan,he & & dinamika \\
& boh & & \\
& Konsep & & \\
& bentuk: & & \\
& menggunakan & & \\
& bentuk musik & & \\
satu bagian. & & \\
\hline
\end{tabular}

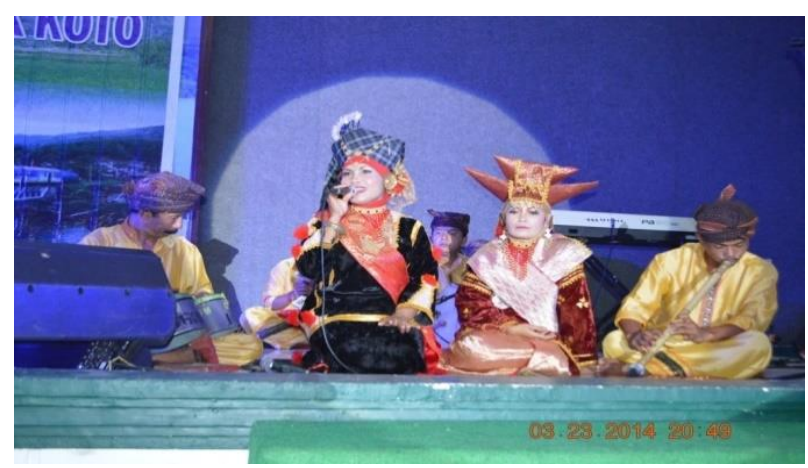

Gambar 1. Pertunjukan Saluang Orgen, oleh : Habib Mar (12 maret 2018).

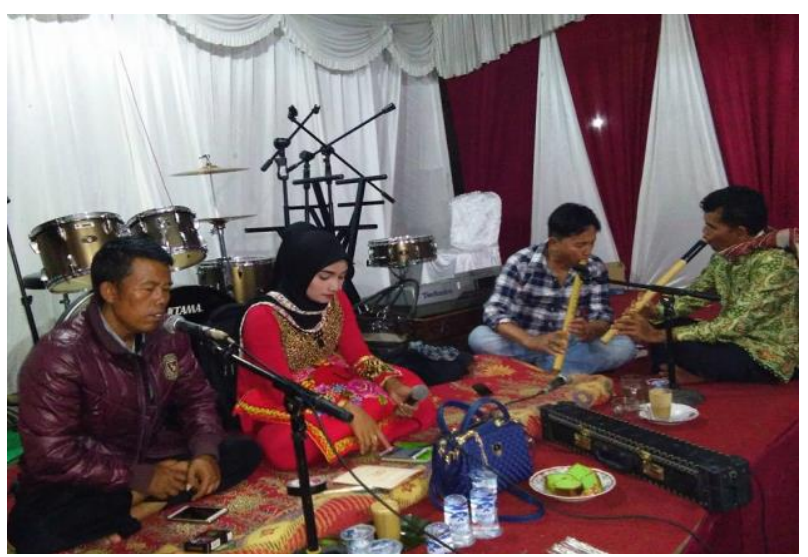

Gambar 1. Pertunjukan Saluang, oleh : Ediwar (12 maret 2018).

\section{B. Metode Penciptaan}

Dalam melahirkan gagasan sesuai dengan rancangan untuk membentuk komposisi musik, perlu adanya tahapan-tahapan kerja dalam melakukan proses pembuatan karya. Proses tersebut dilakukan dengan melakukan pendekatan yaitu :

\section{Metode Pengembangan Konsep}

Metode pengembangan konsep adalah cara atau alat agar nilai-nilai yang terkandung didalam diri seniman dapat tumbuh menjadi pemahaman baru dalam mewujudkan suatu konsep ke dalam sebuah karya seni.Dalam metode pengembangan ini, bagaimana pengkarya memahami konteks dalam konsep karya "Bahoyak" yang dilahirkan dengan menggunakan idiom dendang Jalu-Jalu. Pengembangan dilakukan nantinya dalam proses latihan karya 'Bahoyak' dengan salah satunya menceritakan kepada player konsep karya 'Bahoyak', dan memberikan pemahaman konsep agar tujuan dalam proses penggarapan seimbang antara player dan komposer,sehingga lahirlah sebuah karya dengan kreativitas yang baru sesuai dengan keahlian masingmasing player tersebut.

\section{Metode Mewujudkan Konsep}

Dalam penggarapan karya seni, metode biasanya disebut sebagai teknik yang yang ditempuh untuk memecahkan masalah tertentu dalam proses penciptaan karya seni.

Metode dalam mewujudkan konsep adalah cara atau alat agar model yang berupa gambaran imaginatif seorang seniman pencipta, mewujudkan sebuah karya seni yang didasari oleh bentuk atau tekstur untuk digarap menjadi realitas, empiris yang dapat dinikmati oleh panca indra.

Adapun tahapan metode yang digunakan dalam proses penggarapan karya adalah :

a. Observasi

Observasi merupakan aktivitas atau proses dalam peninjauan dan pengamatan terhadap hal-hal yang berkaitan dengan objek penelitian maupun sumber yang menjadi rujukan dalam proses penciptan sebuah karya seni dengan maksud memahami dari berbagai data-data yang diperlukan berdasarkan pengetahuan dan gagasan yang sudah diketahui sebelumnya, sehingga dapat mengumpulkan informasi-informasi yang dibutuhkan.

Langkah pertama dalam tahap ini observasi, yaitu melakukan apresiasi dan meneliti semua yang pengkarya anggap berhubungan dengan komposisi yang akan pengkarya garap. Selain itu pengkarya juga mengumpulkan data-data yang berhubungan dengan karya yang akan digarap baik yang berasal dari media eletronik maupun media cetak.

b. Eksplorasi

Eksplorasi dalam proses penciptaan karya seni merupakan proses penjelahan atau "pengembaraan jiwa" untuk menggali unsur-unsur baik bentuk maupun konten dan makna dari sebuah karya seni yang akan diciptakan. Bentuk dan makna dalam proses eksplorasi bertujuan untuk megumpulkan data-data yang berkaitan dengan konsep garapan sebuah karya seni.

Pendekatan yang dilakukan pada tahap ini adalah melalui pengamatan dan pengumpulan data. Data dan informasi didapat dari sumber media, serta dengan melakukan ekplorasi langsung terhadap objek yang akan dijadikan sumber penciptaan, kemudian mempresentasikan kembali idiom-idiom musik yang digunakankedalam karya. Proses eksplorasi diakukan terhadap idiom dendang Jalu-Jalu dan instrumen pendukung lainnya yang dikembangkan sesuai dengan capaian karya ' Bahoyak" yang akan dibuat nantinya.

c. Eksperimentasi

Eksperimen (percobaan) dalam proses penciptaan seni merupakan salah satu bagian penting dalam berkesenian. Proses ini tidak hanya dapat mengungkap ide-ide kreatif, namun proses eksperimen juga 
merupakan proses pematangan konsep dan bentuk dari sebuah karya seni, sehingga nantinya ketika karya seni itu disajikan atau ditampilkan dapat menjadi karya yang sesuai dengan yang diharapkan.

Dalam tahap ini dilakukan berbagai macam percobaan (eksperimentasi) untuk berbagai kemungkinan yang diperlukan dengan tindakan seleksi material dan respon penemuan bentuk aspek artistik maupun imajinasi dalam mencapai integritas karya itu sendiri. Salah satu yang dilakukan bereksperimen dalam menciptakan intrumen "lekdaw" dan "dombes". Lekdaw adalah intrumen yang tercipta dari triplek dan dawai, yang dibunyikan secara digesek. Sedangkan "dombas", adalah dorom basi, sebuah eksperimen drum besi yang di padukan dengan besi pita yang dimainkan dengan dipukul.

d. Aplikasi

Pada tahap ini, pemilihan beberpa materi musikal yang telah dirancang sebelumnya, disempurnakan untuk kemudian diaplikasikan ke dalam sebuah karya, di dalam proses yang dilakukan tentu mengalami perkembangan dan perubahan terhadap rancangan sebelumnya sesuai dengan konsep dan proses kreatif dalam pengolahan aspek musikal.

Perkembangan dan perubahan rancangan dalam kesenian merupakan sesuatu hal yang wajar, karena proses ini merupakan bagian dari proses kreatif untuk mematang konsep sehingga karya seni yang diciptakan tidak hanya memberi kepuasan bathin pada pengkaryanya, namun dapat pula memberi kepuasan bagi masyarakat.

\section{Kesimpulan}

Bagurau merupakan pertunjukan tradisional yang berkarakter yang mempunyai cirri khas tersendiri, pendidikan moral, dan juga sebagai tempat pembelajaran kehidupan bagi masyarakat minangkabau.Berbagai macam fenomena yang terjadi sehingga pertunjukan bagurau bisa digolongkan sebagai kesenian tradisional yang sebagai wadah silaturahmi bagi masyarakat. Keunikan dalam fenomena ini terdapat pada metode fungsional yang digunakan oleh masyarakat itu sendiri.Metode tersebut sering disebut oleh masyarakat ajang canda gurau dan mempererat hubungan antarasesama masyarakat.

Bahoyak merupakan sebuah metode penggambaran pengaruh postmodern dalam pertunjunkan saluang gurau. Metode promosi ini dilakukan dengan carabermainnya alat musik yang menginterpretasikan bunyi canda gurau masyarakat yang dipengaruhi postmodren sehingga keunikan metode ini menjadi fenomena baru yang tidak bisa dielakan dalam masyrakat Minangkabau.

\section{Daftar Pustaka}

Halim, M 2008.'”Bagurau Fanatik Masyarakat Darek Minang '.'Laporan karya Program Pasca SarjanaISI Surakarta.
Hardjana, Suka 2003.' 'Coret-Coret Musik Kontemporer Dulu dan Kini", Jakarta: Ford Foundation dan Masyarakat Seni Pertunjukan Indonesia.

Jaya, Indra 2011."'Pado-pado dalam dua dimensi"'.Laporan karya program Pasca sarjana Institut Seni Indonesia Padangpanjang.

Lubis, Akhyar Yusuf 2014.'Postmodernisme Teori dan Metode". Jakarta: PT Rajagrafindo Persada.

Oktavia, Rina 2017.'Penyanyi Orgen Tunggal Sebagai Parodi Dalam Pertunjukan Bagurau Lapiak di Kota Payokumbuh".Tesis Pasca Sarjana ISI Padangpanjang.

Piliang, Yasraf Amir 2003.Hipersemiotika,Tafsir Cultural Studies Atas Matinya Makna.Yogyakarta: Jala Sutra.

Rustim 2010.' Interaksi Sosial Dalam Pertunjukan Tradisi Bagurau Saluang Dendang Di Minangkabau'.Tesis Yogyakarta: Universitas Gadjah Mada.

Sastra, Andar Indra 1999.'”Bagurau Dalam Basaluang :Cerminan Budaya Konflik'”. Tesis, Yogyakarta: Universitas Gadjah Mada.

Supanggah, Rahayu 2009.Bhotekan Karawitan IIGarap, Surakarta: ISI Press.

Supanggah, Rahayu 2005.Garap:Salah Satu Konsep Pendekatan atau Kajian Musik Nusantara, Dalam Waridi, ed. Menimbang Pendekatan Pengkajian dan Penciptaan Musik Nusantara. Surakarta : STSI Press.

Yelly, Nofroza (2012),'Pertunjukan Saluang Orgen Pada Masyarakat Nagari Silayo Kabupaten Solok". Tesis, ISI Padangpanjang.

\section{Daftar Informan}

Abdullah, 49 Tahun, Pekerjaan; Guru dan pengamat seni. Alamat; Bukittinggi. Tanggal Wawancara 15 Januari 2018.

Avandi, 36 Tahun. Pekerjaan; Tukang Ojek dan Pecandu Curau. Alamat; Biaro, IV Angkek Canduang. Tanggal Wawancara 18 Februari 2018.

Boni, 28 Tahun. Pekerjaan; Sopir Angkot dan Pecandu Gurau. Alamat; Balai-Balai Padangpanjang. Tanggal Wawancara 20 Otober 2017.

Dodi, 43 Tahun. Pekerjaan; Usaha Warung. Alamat; Balai-Balai Padangpanjang. Tanggal Wawancara 3 Maret 2018.

Ersita, 43 Tahun. Pekerjaan; Tukang Dendang. Alamat; Batusangkar. Tanggal Wawancara; 3 Januari 2018.

M. Halim. 56 Tahun. Pekerjaan; Dosen ISI Padangpanjang. Alamat; Padangpanjang. Tanggal Wawancara; 3 Januari 2018 